\title{
Perirenal fat thickness is associated with metabolic risk factors in patients with chronic kidney disease
}

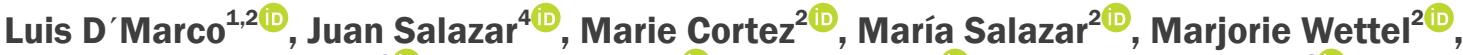 \\ Marcos Lima-Martínez ${ }^{3 \text { (D) }}$, Edward Rojas ${ }^{5(\mathbb{E})}$, Willy Roque ${ }^{5(\mathbb{E})}$, Valmore Bermúdez $^{4(\mathbb{D})}$ \\ ${ }^{7}$ Consorci Sanitari del Garraf, Servicio de Nefrología, Barcelona, Spain \\ ${ }^{2}$ Advanced Unit of Renal Sonographic Diagnostics, Puerto Ordaz Clinic, Puerto Ordaz City, Venezuela \\ ${ }^{3}$ Department of Physiological Sciences, Universidad de Oriente, Bolivar, Venezuela \\ ${ }^{4}$ Universidad Simon Bolivar Facultad de Ciencias de la Salud, Barranquilla, Colombia \\ ${ }^{5}$ Rutgers, The State University of New Jersey, New Brunswick, NJ, USA
}

\begin{abstract}
Background: Adipose tissue accumulation in specific body compartments has been associated with diabetes, hypertension and dyslipidemia. Perirenal fat (PRF) may lead to have direct lipotoxic effects on renal function and intrarenal hydrostatic pressure. This study was undertaken to explore the association of PRF with cardiovascular risk factors and different stages of chronic kidney disease (CKD).

Methods: We studied 103 patients with CKD of different stages (1 to 5). PRF was measured by B-mode renal ultrasonography in the distal third between the cortex and the hepatic border and/or spleen.

Results: The PRF thickness was greater in CKD patients with impaired fasting glucose than in those with normal glucose levels $(1.10 \pm 0.40 \mathrm{~cm}$ vs. $0.85 \pm 0.39 \mathrm{~cm}, P<0.01$ ). Patients in CKD stages 4 and 5 (glomerular filtration rate $[\mathrm{GFR}]<30 \mathrm{~mL} / \mathrm{min} / 1.73 \mathrm{~m}^{2}$ ) had the highest PRF thickness. Serum triglyceride levels correlated positively with the PRF thickness; the PRF thickness was greater in patients with triglyceride levels $\geq 150 \mathrm{mg} / \mathrm{dL}(1.09 \pm 0.40 \mathrm{~cm}$ vs. $0.86 \pm 0.36 \mathrm{~cm}, P<0.01$ ). In patients with a GFR $<60 \mathrm{~mL} / \mathrm{min} / 1.73 \mathrm{~m}^{2}$, uric acid levels correlated positively with the PRF thickness $(P<0.05)$.

Conclusion: In CKD patients, the PRF thickness correlated significantly with metabolic risk factors that could affect kidney function.
\end{abstract}

Keywords: Cardiovascular, Chronic kidney disease, Diabetes, Metabolic risk, Perirenal fat, Renal insufficiency

Received December 12, 2018; Revised March 30, 2019;

Accepted April 11, 2019

Edited by Won Kim, Chonbuk National University, Jeonju, Korea Correspondence: Luis D'Marco

Consorci Sanitari del Garraf, Servicio de Nefrología, Barcelona 08811, Spain. E-mail: luisgerardodg@hotmail.com

Copyright (C) 2019 by The Korean Society of Nephrology

(a) This is an open-access article distributed under the terms of the Creative Commons Attribution Non-Commercial License (http://creativecommons. org/licenses/by-nc-nd/4.0/), which permits unrestricted non-commercial use, distribution, and reproduction in any medium, provided the original work is properly cited.

\section{Introduction}

Chronic kidney disease (CKD) is defined as an abnormality of kidney structure or function, present for $>3$ months, with implications for health $[1,2]$. CKD is often associated with chronic inflammatory processes, and is strongly associated with cardiovascular and metabolic risk factors [3]. Patients with CKD are at greater risk for cardiovascular events, hypertension, left ventricular hypertrophy and coronary artery disease than other populations at risk [4].

Metabolic risk factors have also been associated with CKD $[5,6]$. Several studies have revealed than an elevated body mass index (BMI) is associated with the progression 
of CKD. Hsu et al [7] observed this association even after adjusting for the presence of hypertension and diabetes mellitus. A meta-analysis including 247 studies revealed that obesity increased the risk of renal disease, and this relationship appeared to be stronger among women $[8,9]$.

The presence of adipose tissue in specific body compartments has been linked to metabolic derangements. Fat deposition in the liver (or non-alcoholic fatty liver) or skeletal muscle has been demonstrated to increase cardiometabolic risk $[10,11]$. Additionally, epicardial adipose tissue is in close relationship with myocardial metabolism via endocrine and paracrine mechanisms $[12,13]$. Recent evidence has revealed increased morbidity and mortality in patients with greater epicardial adiposity $[14,15]$. Perirenal fat (PRF) has been associated with direct lipotoxic effects on the kidneys, such as increasing the glomerular hydrostatic pressure, activating the renin-angiotensin-aldosterone system and accelerating the progression to kidney disease [16-18].

Several non-invasive methods of measuring the distribution of body fat have allowed physicians to explore its association with specific conditions, especially via computed tomography (CT) and magnetic resonance imaging (MRI) [19-21]. However, exposure to radiation and high costs has hindered the use of these imaging strategies in larger-scale studies on this association. Armellini et al [22] demonstrated that ultrasonographic imaging is a feasible alternative to CT and MRI, considering that this imaging strategy entails no radiation exposure and is cheap and reproducible. Kawasaki et al [23] later expanded this approach by evaluating the use of an abdominal ultrasound to determine the amount of PRF. The association of PRF with abdominal obesity has been implicated in the microalbuminuria detected in obese patients [24]. Although some studies have described the association of PRF with the progression of CKD in type 2 diabetic patients, the presence of PRF has been poorly studied in patients with CKD [25].

The aim of this study was to evaluate the relationship between the PRF thickness and the presence of cardiometabolic risk factors in CKD patients.

\section{Methods}

Study patients

This cohort study included 103 patients with prior diag- noses of CKD with glomerular filtration rate (GFR) grades 1 to 5 . All the patients were evaluated at the UNIRENAL Center, Puerto Odaz city in Venezuela from January to November 2015. Informed consent was obtained from all patients and was approved from the institutional review board of the institution. We used the Kidney Disease Improving Global Outcomes (KDIGO) 2012 definition of CKD: an abnormality of kidney structure or function, present for $>3$ months, with implications for health. The CKD Epidemiology Collaboration (CKD-EPI) equation was used to calculate the estimated GFR (eGFR). We used the CKD classification guidelines introduced by the National Kidney Foundation (NKF) Kidney Disease Outcomes Quality Initiative (KDOQI) in 2002, which define a GFR (in $\mathrm{mL} / \mathrm{min} / 1.73 \mathrm{~m}^{2}$ ) of $>90$ as CKD stage 1 , of 60 to 89 as CKD stage 2, of 30 to 59 as CKD stage 3, of 15 to 29 as CKD stage 4 , and of $<15$ as CKD stage 5 . Patients with an acute kidney injury, polycystic kidney disease or CKD requiring renal replacement therapy were excluded.

Arterial hypertension was defined as a systolic blood pressure (SBP) $\geq 140 \mathrm{mmHg}$, a diastolic blood pressure (DBP) $\geq 90 \mathrm{mmHg}$ or the use of antihypertensive drugs. A diagnosis of diabetes mellitus was established when the fasting glucose level was $\geq 126 \mathrm{mg} / \mathrm{dL}$ or the patient used antidiabetic medications. Dyslipidemia was recognized as a low-density lipoprotein cholesterol (LDL-C) level $\geq 100$ $\mathrm{mg} / \mathrm{dL}$, a total cholesterol level $\geq 200 \mathrm{mg} / \mathrm{dL}$, a triglyceride level $\geq 150 \mathrm{mg} / \mathrm{dL}$ or the use of medications for dyslipidemia. Hyperuricemia was defined as a serum uric acid level $\geq 6.5 \mathrm{mg} / \mathrm{dL}$.

Patients were evaluated after 8 to 12 hours of fasting and a 15-minute resting period. Blood samples were collected and stored at $4^{\circ} \mathrm{C}$ to $15^{\circ} \mathrm{C}$. Samples were centrifuged for 15 minutes and processed by absorbent photometry and turbidometry on an automatized analyzer (MINDRAY ${ }^{\circledR}$ model: BS-240 China; Mindray Medical International Limited, Shenzhen, China).

\section{Imaging}

The thickness of the PRF was measured in centimeters (cm) through a B-mode ultrasound with a 3.5-MHz convex transductor (Alpinion ${ }^{\circledR}$ E-CUBE 9; Alpinion Medical Systems, Seoul, Korea). Patients underwent a bilateral renal ultrasound, and the kidneys were measured anteriorposteriorly, transversally and longitudinally. PRF was 
measured in the distal third between the cortex and the hepatic border and/or spleen (Fig. 1).

\section{Statistical analysis}

Qualitative variables are shown as absolute and relative frequencies. The chi-square $\left(\chi^{2}\right)$ test was used to determine the association between variables. Quantitative

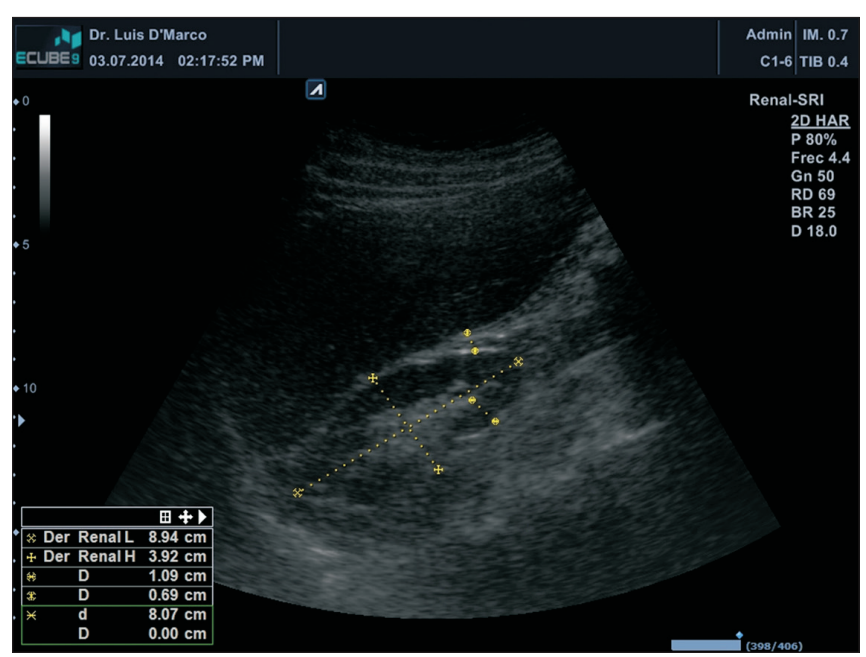

Figure 1. Perirenal fat thickness measurement. Perirenal fat was measured in the distal third between the cortex and the hepatic border and/or spleen. variables are shown as the mean and standard deviation. A Kolmogorov-Smirnov normality test was used to determine normality, and non-normal variables were transformed to new logarithmic variables for analysis. We compared means using Student's $t$ test for two groups and one-factor analysis of variance (ANOVA) for three or more variables with Tukey's post-hoc analysis. SPSS version 19.0 (IBM Corp., Armonk, NY, USA) for Windows was used for all statistical tests. A $P$ value $<0.05$ was considered significant.

\section{Results}

\section{General characteristics and PRF thickness}

We studied 103 patients $(64.1 \%$ female $[\mathrm{n}=66]$ and $35.9 \%$ male $[n=37])$. The mean age was $55 \pm 16$ years. The DBP, urea, creatinine, high-density lipoprotein cholesterol (HDL-C) and PRF levels differed significantly between men and women (Table 1). The PRF thickness was significantly greater in men than in women $(1.10 \pm 0.45$ cm vs. $0.86 \pm 0.35 \mathrm{~cm}, P=0.005$; Table 1$)$.

\section{Clinical and biochemical characteristics and PRF thickness}

Fig. 2 displays the distribution of diabetic patients ac-

Table 1. General characteristics and thickness of perirenal fat

\begin{tabular}{|c|c|c|c|c|}
\hline Characteristic & Total $(n=103)$ & Female $(n=66)$ & Male $(n=37)$ & $P$ value \\
\hline Age (yr) & $55 \pm 16$ & $53 \pm 15$ & $57 \pm 18$ & 0.20 \\
\hline Body mass index $\left(\mathrm{kg} / \mathrm{m}^{2}\right)$ & $28.0 \pm 5.2$ & $28.1 \pm 5.6$ & $27.7 \pm 4.5$ & 0.69 \\
\hline Waist circumference (cm) & $95.3 \pm 12.9$ & $95.2 \pm 12.5$ & $95.6 \pm 14.2$ & 0.93 \\
\hline Systolic blood pressure (mmHg) & $142.3 \pm 24.3$ & $142.5 \pm 25.9$ & $142.1 \pm 21.8$ & 0.95 \\
\hline Diastolic blood pressure (mmHg) & $80.7 \pm 12.9$ & $82.9 \pm 11.4$ & $76.9 \pm 14.6$ & 0.05 \\
\hline Glucose (mg/dL) & $107.4 \pm 33.8$ & $107.9 \pm 37.0$ & $106.5 \pm 27.7$ & 0.85 \\
\hline Urea (mg/dL) & $55.5 \pm 42.5$ & $49.2 \pm 36.2$ & $67.5 \pm 51.0$ & 0.05 \\
\hline Creatinine (mg/dL) & $1.6 \pm 1.7$ & $1.4 \pm 1.2$ & $2.1 \pm 2.3$ & 0.04 \\
\hline Total cholesterol (mg/dL) & $193.7 \pm 44.6$ & $197.7 \pm 42.2$ & $186.7 \pm 48.2$ & 0.30 \\
\hline $\mathrm{HDL}-\mathrm{C}(\mathrm{mg} / \mathrm{dL})$ & $46.2 \pm 14.5$ & $48.5 \pm 15.4$ & $41.9 \pm 12.0$ & 0.04 \\
\hline LDL-C (mg/dL) & $117.4 \pm 40.2$ & $117.4 \pm 39.9$ & $117.5 \pm 41.4$ & 0.99 \\
\hline VLDL-C (mg/dL) & $28.6 \pm 14.7$ & $28.4 \pm 14.4$ & $29.0 \pm 15.6$ & 0.89 \\
\hline Triglycerides (mg/dL) & $153.0 \pm 82.2$ & $151.9 \pm 85.2$ & $154.9 \pm 78.1$ & 0.87 \\
\hline Uric acid (mg/dL) & $5.3 \pm 2.0$ & $4.9 \pm 2.1$ & $5.9 \pm 1.6$ & 0.06 \\
\hline Resistance index & $0.70 \pm 0.09$ & $0.72 \pm 0.09$ & $0.67 \pm 0.10$ & 0.30 \\
\hline Perirenal fat (cm) & $0.95 \pm 0.40$ & $0.86 \pm 0.35$ & $1.10 \pm 0.45$ & $<0.01$ \\
\hline
\end{tabular}

Data are presented as the mean \pm standard deviation. Comparisons between the male and female groups were made by Student's $t$ test after log transformation. HDL-C, high-density lipoprotein cholesterol; LDL-C, low-density lipoprotein cholesterol; VLDL-C, very low-density lipoprotein cholesterol. 
cording to their eGFR values. Patients with diabetes mellitus had lower eGFR values than non-diabetic patients $(P<0.05)$. The patients in CKD stage 1 were significantly younger than those in CKD stages 2,3 , or 4 and $5(P<$ 0.001 , Table 2). The SBP was significantly higher in CKD stage 4 and 5 patients than in stage 1 patients $(P<0.001$, Table 2). Uric acid levels were significantly higher in patients in CKD stages 2, 3 or 4 and 5 than in patients in

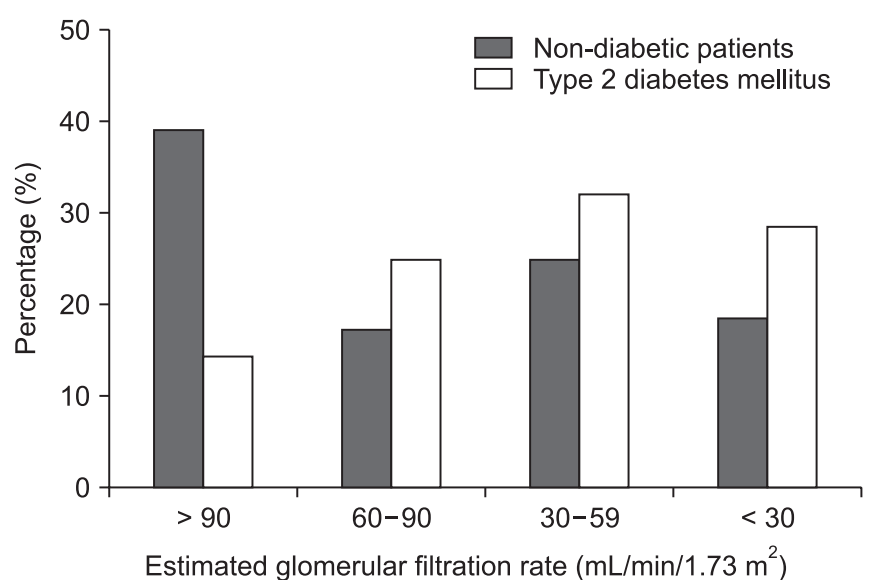

Figure 2. Distribution of diabetes mellitus patients according to the estimated glomerular filtration rate.
CKD stage $1(P<0.001$, Table 2$)$. The thickness of the PRF tended to be greater in CKD stage 4 and 5 patients than in stage 1 patients; however, the difference did not reach statistical difference (Table 2).

\section{Thickness of the PRF according to age and metabolic determinants}

We found that the thickness of the PRF was associated with age, as shown in Table 3. The PRF thickness started to increase at age $45(P=0.02$, Table 3$)$. We also explored the relationship between PRF thickness and metabolic parameters such as fasting glucose levels, lipid profiles and blood uric acid levels (Table 4). The thickness of the PRF was significantly higher in the high fasting glucose group than in the low fasting glucose group $(P<0.01$, Table 4). Patients with elevated triglyceride levels had a thicker PRF layer than those with lower triglyceride levels $(1.09 \pm 0.40 \mathrm{~cm}$ vs. $0.86 \pm 0.36 \mathrm{~cm} ; P<0.01$, Table 4$)$. Patients with hyperuricemia also had a thicker PRF layer than their counterparts $(1.13 \pm 0.43 \mathrm{~cm}$ vs. $0.86 \pm 0.36 \mathrm{~cm}$, $P=0.02$, Table 4 ).

Table 2. Clinical and biochemical characteristics and perirenal fat thickness according to the estimated glomerular filtration rate

\begin{tabular}{|c|c|c|c|c|c|}
\hline \multirow[b]{2}{*}{ Characteristic } & \multicolumn{4}{|c|}{ CKD stage $\left(\mathrm{mL} / \mathrm{min} / 1.73 \mathrm{~m}^{2}\right)$} & \multirow[b]{2}{*}{$P$ value* } \\
\hline & $\begin{array}{c}\text { CKD stage } 1 \\
(\geq 90)\end{array}$ & $\begin{array}{l}\text { CKD stage } 2 \\
\text { (60 to } 89)\end{array}$ & $\begin{array}{l}\text { CKD stage } 3 \\
\text { (30 to 59) }\end{array}$ & $\begin{array}{c}\text { CKD stages } 4 \text { and } 5 \\
(<30)\end{array}$ & \\
\hline Age (yr) & $42 \pm 14$ & $54 \pm 12^{*}$ & $64 \pm 11^{t \dagger \dagger}$ & $60 \pm 15^{\# \# \#}$ & $<0.01$ \\
\hline Body mass index $\left(\mathrm{kg} / \mathrm{m}^{2}\right)$ & $29.1 \pm 6.5$ & $26.5 \pm 3.1$ & $27.8 \pm 4.4$ & $25.7 \pm 2.6$ & 0.09 \\
\hline Waist circumference (cm) & $97.9 \pm 15.3$ & $82.0 \pm 0.7$ & $99.2 \pm 10.5$ & $89.5 \pm 10.4$ & 0.25 \\
\hline Systolic blood pressure (mmHg) & $128.4 \pm 16.5$ & $145.5 \pm 22.1$ & $150.4 \pm 24.8^{\dagger \dagger}$ & $155.2 \pm 27.4^{\# \#}$ & $<0.01$ \\
\hline Diastolic blood pressure (mmHg) & $80.0 \pm 10.2$ & $75.8 \pm 16.8$ & $82.0 \pm 12.1$ & $80.1 \pm 17.1$ & 0.64 \\
\hline Glucose $(\mathrm{mg} / \mathrm{dL})$ & $97.6 \pm 25.2$ & $121.0 \pm 49.7$ & $120.6 \pm 38.3^{\dagger}$ & $102.0 \pm 27.7$ & 0.05 \\
\hline Total cholesterol (mg/dL) & $188.5 \pm 37.9$ & $192.8 \pm 25.3$ & $206.8 \pm 61.3$ & $203.3 \pm 47.8$ & 0.51 \\
\hline $\mathrm{HDL}-\mathrm{C}(\mathrm{mg} / \mathrm{dL})$ & $45.8 \pm 13.0$ & $46.3 \pm 12.8$ & $47.0 \pm 22.4$ & $46.3 \pm 8.7$ & 0.99 \\
\hline LDL-C (mg/dL) & $115.9 \pm 33.5$ & $111.8 \pm 26.0$ & $126.5 \pm 53.6$ & $135.2 \pm 45.1$ & 0.50 \\
\hline VLDL-C (mg/dL) & $25.4 \pm 16.2$ & $33.2 \pm 14.2$ & $32.5 \pm 16.1$ & $29.4 \pm 6.7$ & 0.40 \\
\hline Triglycerides (mg/dL) & $129.4 \pm 77.2$ & $181.7 \pm 91.9$ & $179.7 \pm 97.1$ & $160.1 \pm 59.9$ & 0.13 \\
\hline Uric acid (mg/dL) & $4.2 \pm 1.5$ & $4.7 \pm 1.1$ & $6.9 \pm 2.0^{\dagger \dagger \dagger}$ & $6.5 \pm 2.1^{\# \# \#}$ & $<0.01$ \\
\hline Resistance index & $0.62 \pm 0.09$ & $0.67 \pm 0.14$ & $0.72 \pm 0.06$ & $0.70 \pm 0.04$ & 0.30 \\
\hline Perirenal fat (cm) & $0.90 \pm 0.38$ & $0.84 \pm 0.40$ & $0.96 \pm 0.37$ & $1.01 \pm 0.45$ & 0.54 \\
\hline
\end{tabular}

Data are presented as the mean \pm standard deviation. Comparisons were made by ANOVA after log transformation.

HDL-C, high-density lipoprotein cholesterol; LDL-C, low-density lipoprotein cholesterol; VLDL-C, very low-density lipoprotein cholesterol.

${ }^{*} P<0.05$ vs. CKD stage 1 on post-hoc test after ANOVA. ${ }^{\dagger} P<0.05$ vs. CKD stage 1 on post-hoc test after ANOVA. ${ }^{\dagger \dagger} P<0.01$ vs. CKD stage 1 on post-hoc test after ANOVA. ${ }^{\dagger \dagger t} P<0.001$ vs. CKD stage 1 on post-hoc test after ANOVA. ${ }^{\# \#} P<0.01$ vs. CKD stage 1 on post-hoc test after ANOVA. ${ }^{\# \#} P<0.001$ vs. CKD stage 1 on posthoc test after ANOVA. 
Table 3. Thickness of perirenal fat according to age and cardiovascular disease risk factors

\begin{tabular}{|c|c|c|}
\hline & Thickness of perirenal fat $(\mathrm{cm})$ & $P$ value \\
\hline Age group (yr) & & 0.02 \\
\hline$<45(n=26)$ & $0.75 \pm 0.30$ & \\
\hline $45-55(n=21)$ & $1.09 \pm 0.45^{*}$ & \\
\hline $56-65(n=24)$ & $1.00 \pm 0.41^{*}$ & \\
\hline$>65(n=32)$ & $0.97 \pm 0.39 *$ & \\
\hline Smoking & & 0.93 \\
\hline No $(n=85)$ & $0.95 \pm 0.40$ & \\
\hline Yes $(n=18)$ & $0.95 \pm 0.43$ & \\
\hline Hypertension & & 0.08 \\
\hline No $(n=37)$ & $0.85 \pm 0.31$ & \\
\hline Yes $(n=66)$ & $1.00 \pm 0.44$ & \\
\hline Type 2 diabetes mellitus & & 0.15 \\
\hline No $(n=74)$ & $0.92 \pm 0.42$ & \\
\hline Yes $(n=29)$ & $1.00 \pm 0.35$ & \\
\hline Prior vascular event ${ }^{a}$ & & 0.31 \\
\hline No $(n=37)$ & $0.89 \pm 0.37$ & \\
\hline Yes $(n=65)$ & $0.98 \pm 0.42$ & \\
\hline \multicolumn{2}{|c|}{ Number of antihypertensive drugs } & 0.83 \\
\hline None $(n=29)$ & $0.98 \pm 0.44$ & \\
\hline $1(n=36)$ & $0.91 \pm 0.38$ & \\
\hline $2(n=31)$ & $0.94 \pm 0.41$ & \\
\hline 3 or more $(n=7)$ & $1.04 \pm 0.40$ & \\
\hline Statin use ${ }^{a}$ & & 0.62 \\
\hline No $(n=81)$ & $0.96 \pm 0.40$ & \\
\hline Yes $(n=21)$ & $0.91 \pm 0.42$ & \\
\hline \multicolumn{2}{|c|}{ Use of medications for proteinuria } & 0.49 \\
\hline No $(n=76)$ & $0.93 \pm 0.40$ & \\
\hline Yes $(n=27)$ & $0.99 \pm 0.40$ & \\
\hline
\end{tabular}

Data are presented as the mean \pm standard deviation.

${ }^{a}$ The total number of patients was 102 due to one missing value. Comparisons were made by Student's $t$ test or ANOVA after log transformation.

$\star P<0.05$ vs. $<45$ group on post-hoc test after ANOVA.

\section{Thickness of the PRF according to CKD stages and} metabolic determinants

We next evaluated the differences in PRF thickness in patients grouped according to CKD stage and particular metabolic determinants. In CKD stage 1 patients, the PRF thickness was significantly greater in those with elevated fasting glucose and triglyceride levels than in those with lower glucose and triglyceride levels (Table 5).

We also examined metabolic determinants after dividing patients into tertiles of PRF thickness. Hyperuricemia was associated with increased PRF levels $(P=0.03$, Fig. 3$)$.
Table 4. Thickness of perirenal fat accoridng to metabolic determinants

\begin{tabular}{|c|c|c|}
\hline & Thickness of perirenal fat $(\mathrm{cm})$ & $P$ value \\
\hline Fasting glucose $(\mathrm{mg} / \mathrm{dL})$ & & $<0.01$ \\
\hline$<100(n=42)$ & $0.85 \pm 0.39$ & \\
\hline$\geq 100(n=21)^{a}$ & $1.10 \pm 0.40$ & \\
\hline Total cholesterol (mg/dL) & & 0.82 \\
\hline$<200(n=44)$ & $0.98 \pm 0.47$ & \\
\hline$\geq 200(n=38)$ & $0.96 \pm 0.35$ & \\
\hline HDL-C (mg/dL) & & 0.12 \\
\hline Normal $(n=33)$ & $0.90 \pm 0.44$ & \\
\hline $\operatorname{Low}(n=40)^{b}$ & $1.02 \pm 0.42$ & \\
\hline LDL-C (mg/dL) & & 0.59 \\
\hline$<100(n=6)$ & $1.14 \pm 0.68$ & \\
\hline$\geq 100(n=64)$ & $0.94 \pm 0.40$ & \\
\hline Triglycerides (mg/dL) & & $<0.01$ \\
\hline$<150(n=45)$ & $0.86 \pm 0.36$ & \\
\hline$\geq 150(n=36)$ & $1.09 \pm 0.40$ & \\
\hline Uric acid (mg/dL) & & 0.02 \\
\hline$<6.5(n=51)$ & $0.86 \pm 0.36$ & \\
\hline$\geq 6.5(n=12)$ & $1.13 \pm 0.43$ & \\
\hline
\end{tabular}

Data are presented as the mean \pm standard deviation. Note that the sum of the groups is not equal to 103 . This is because of missing values for these variables. Comparisons between two groups were made by Student's $t$ test after log transformation.

HDL-C, high-density lipoprotein cholesterol; LDL-C, low-density lipoprotein cholesterol.

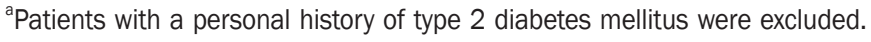
${ }^{\mathrm{b}} \mathrm{HDL}-\mathrm{C}$ levels $<40 \mathrm{mg} / \mathrm{dL}$ and $<50 \mathrm{mg} / \mathrm{dL}$ were used as the reference values for the low HDL-C group in men and women, respectively.

\section{Discussion}

The first report associating obesity with microalbuminuria came from Weisinger et al in 1974 [26]. More recent research has validated their results, demonstrating that de novo kidney disease can be induced by obesity. Visceral adipose tissue is a well-known risk factor for diabetes and hypertension, and these two diseases are the main causes of end-stage renal disease requiring renal replacement therapy [27-30].

Our study revealed that CKD patients with abnormal fasting glucose levels had thicker PRF layers than normoglycemic CKD patients. Patients in CKD stage 1 tended to have thicker PRF layers than other GFR groups; however, this finding was not statistically significant. Lamacchia et al [25] suggested that the PRF is an independent risk factor for a worsening GFR. Nonetheless, despite adjust- 
Table 5. Thickness of perirenal fat according to CKD stage and metabolic determinants

\begin{tabular}{|c|c|c|c|c|}
\hline & \multicolumn{4}{|c|}{ CKD stage $\left(\mathrm{mL} / \mathrm{min} / 1.73 \mathrm{~m}^{2}\right)$} \\
\hline & CKD stage $1(\geq 90)$ & CKD stage 2 (60 to 89) & CKD stage 3 (30 to 59) & CKD stages 4 and $5(<30)$ \\
\hline \multicolumn{5}{|c|}{ Fasting glucose (mg/dL) } \\
\hline$<100$ & $0.85 \pm 0.39(n=22)$ & $0.57 \pm 0.20(n=3)$ & $0.90 \pm 0.48(n=7)$ & $0.79 \pm 0.30(n=5)$ \\
\hline$\geq 100^{\mathrm{a}}$ & $1.04 \pm 0.18(n=7)^{*}$ & $0.71 \pm 0.06(n=3)$ & $1.18 \pm 0.29(n=6)$ & $1.66 \pm 0.77(n=2)$ \\
\hline \multicolumn{5}{|c|}{ Triglycerides (mg/dL) } \\
\hline$<150$ & $0.84 \pm 0.37(n=23)$ & $0.69 \pm 0.11(n=6)$ & $0.86 \pm 0.38(n=8)$ & $0.99 \pm 0.30(n=3)$ \\
\hline$\geq 150$ & $1.16 \pm 0.46(n=7)^{*}$ & $0.99 \pm 0.48(n=9)$ & $1.09 \pm 0.33(n=9)$ & $1.11 \pm 0.54(n=9)$ \\
\hline \multicolumn{5}{|c|}{ Uric acid (mg/dL) } \\
\hline$<6.5$ & $0.89 \pm 0.42(n=24)$ & $0.73 \pm 0.85(n=12)$ & $0.78 \pm 0.30(n=7)$ & $1.02 \pm 0.40(n=7)$ \\
\hline$\geq 6.5$ & $1.13 \pm 0.55(n=2)$ & $(n=0)$ & $1.10 \pm 0.21(n=5) *$ & $1.17 \pm 0.61(n=5)$ \\
\hline
\end{tabular}

Data are presented as the mean \pm standard deviation (number). Note that the sum of the groups is not equal to 103 . This is because of missing values for these variables. Comparisons between two groups were made by Student's $t$ test after log transformation.

CKD, chronic kidney disease.

${ }^{a}$ Patients with a personal history of type 2 diabetes mellitus were excluded.

$\star P<0.05$ between the two groups in each CKD stage.

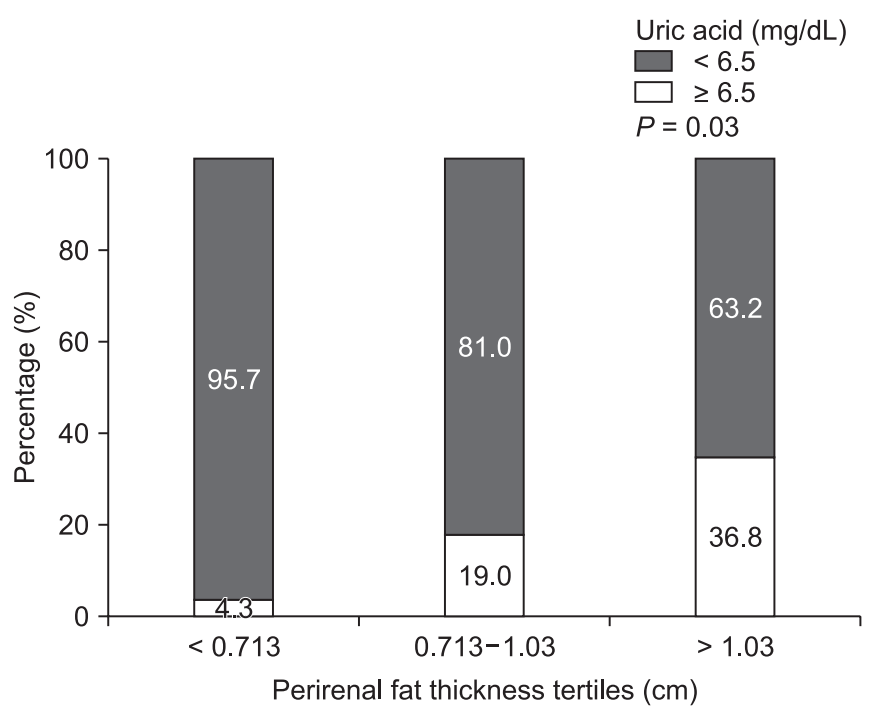

Figure 3. Distribution of patients according to tertile of perirenal fat and uric acid levels.

ing for BMI and using different calculation formulas to determine the GFR, these factors may represent possible confounders.

Common risk factors for coronary artery disease are highly prevalent in CKD patients. CKD patients exhibit increased rates of acute coronary events, and dyslipidemia is a common risk factor associated with reduced kidney function [31-33]. In CKD patients, the initial change in lipid metabolism is a reduction in HDL-C levels due to reduced ApoA and ApoA II levels, as well as an increase in triglyceride levels due to reduced clearance
[34]. Paradoxically, patients with better kidney function had higher triglyceride levels. The small sample size may have impeded us from observing higher triglyceride levels among CKD patients; nonetheless, we did observe that those with triglyceride levels $>150 \mathrm{mg} / \mathrm{dL}$ had thicker PRF layers.

We did not observe significant differences in PRF thickness according to the total cholesterol, LDL-C or HDL$\mathrm{C}$ level. Interestingly, animal models have demonstrated that statins reduce the PRF thickness [35].

Hyperuricemia is associated with increased cardiovascular risk [36-38] and has been identified as a marker of renal disease $[39,40]$. In our study, uric acid levels differed significantly across different stages of CKD. Those with a GFR $<60 \mathrm{~mL} / \mathrm{min} / 1.73 \mathrm{~m}^{2}$ exhibited elevated uric acid levels, along with thicker PRF.

The main limitation of our study was the small sample size and the lack of data on additional metabolic and inflammatory biomarkers, such as the erythrocyte sedimentation rate, C-reactive protein, cystatin $\mathrm{C}$ and asymmetric dimethylarginine levels. This may explain why we did not observe an association between CKD progression and PRF thickness. Nonetheless, our results revealed metabolic risk factors that correlated significantly with PRF thickness, which may affect kidney function. It remains to be determined whether there is a direct relationship between PRF and renal disease. 


\section{Conflicts of interest}

All authors have no conflicts of interest to declare.

\section{Authors' contributions}

All authors participated in the study design and coordination and helped to draft the manuscript. All authors read and approved the final manuscript.

\section{References}

[1] Levey AS, de Jong PE, Coresh J, et al. The definition, classification, and prognosis of chronic kidney disease: a KDIGO Controversies Conference report. Kidney Int 2011;80:17-28.

[2] KDIGO CKD Work Group. Kidney Disease: Improving Global Outcomes (KDIGO) CKD Work Group. KDIGO 2012 clinical practice guideline for the evaluation and management of chronic kidney disease. Kidney Int Suppl 2013;3:1150.

[3] Tonelli M, Wiebe N, Culleton B, et al. Chronic kidney disease and mortality risk: a systematic review. J Am Soc Nephrol 2006; 17:2034-2047.

[4] Go AS, Chertow GM, Fan D, McCulloch CE, Hsu CY. Chronic kidney disease and the risks of death, cardiovascular events, and hospitalization. N Engl J Med 2004;351:12961305.

[5] Leavey SF, McCullough K, Hecking E, Goodkin D, Port FK, Young EW. Body mass index and mortality in 'healthier' as compared with 'sicker' haemodialysis patients: results from the Dialysis Outcomes and Practice Patterns Study (DOPPS). Nephrol Dial Transplant 2001;16:2386-2394.

[6] Kalaitzidis RG, Siamopoulos KC. The role of obesity in kidney disease: recent findings and potential mechanisms. Int Urol Nephrol 2011;43:771-784.

[7] Hsu CY, McCulloch CE, Iribarren C, Darbinian J, Go AS. Body mass index and risk for end-stage renal disease. Ann Intern Med 2006;144:21-28.

[8] Wang Y, Chen X, Song Y, Caballero B, Cheskin LJ. Association between obesity and kidney disease: a systematic review and meta-analysis. Kidney Int 2008;73:19-33.

[9] Garofalo C, Borrelli S, Minutolo R, Chiodini P, De Nicola L, Conte G. A systematic review and meta-analysis suggests obesity predicts onset of chronic kidney disease in the general population. Kidney Int 2017;91:1224-1235.

[10] Speliotes EK, Massaro JM, Hoffmann U, et al. Fatty liver is associated with dyslipidemia and dysglycemia independent of visceral fat: the Framingham Heart Study. Hepatology 2010;51:1979-1987.

[11] Meshkani R, Adeli K. Hepatic insulin resistance, metabolic syndrome and cardiovascular disease. Clin Biochem 2009;42:1331-1346.

[12] Iacobellis G, Bianco AC. Epicardial adipose tissue: emerging physiological, pathophysiological and clinical features. Trends Endocrinol Metab 2011;22:450-457.

[13] Bettencourt N, Toschke AM, Leite D, et al. Epicardial adipose tissue is an independent predictor of coronary atherosclerotic burden. Int J Cardiol 2012;158:26-32.

[14] D’Marco LG, Bellasi A, Kim S, Chen Z, Block GA, Raggi P. Epicardial adipose tissue predicts mortality in incident hemodialysis patients: a substudy of the Renagel in New Dialysis trial. Nephrol Dial Transplant 2013;28:2586-2595.

[15] Karohl C, D'Marco L, Bellasi A, Raggi P. Hybrid myocardial imaging for risk stratification prior to kidney transplantation: added value of coronary calcium and epicardial adipose tissue. J Nucl Cardiol 2013;20:1013-1020.

[16] Rea DJ, Heimbach JK, Grande JP, et al. Glomerular volume and renal histology in obese and non-obese living kidney donors. Kidney Int 2006;70:1636-1641.

[17] Chughtai HL, Morgan TM, Rocco M, et al. Renal sinus fat and poor blood pressure control in middle-aged and elderly individuals at risk for cardiovascular events. Hypertension 2010;56:901-906.

[18] Montani JP, Carroll JF, Dwyer TM, Antic V, Yang Z, Dulloo AG. Ectopic fat storage in heart, blood vessels and kidneys in the pathogenesis of cardiovascular diseases. Int J Obes Relat Metab Disord 2004;28 Suppl 4:S58-S65.

[19] Vogt FM, Ruehm S, Hunold P, et al. [Rapid total body fat measurement by magnetic resonance imaging: quantification and topography]. Rofo 2007;179:480-486. German.

[20] Tokunaga K, Matsuzawa Y, Ishikawa K, Tarui S. A novel technique for the determination of body fat by computed tomography. Int J Obes 1983;7:437-445.

[21] Stallone DD, Stunkard AJ, Wadden TA, Foster GD, Boorstein J, Arger P. Weight loss and body fat distribution: a feasibility study using computed tomography. Int J Obes 1991;15:775780.

[22] Armellini F, Zamboni M, Rigo L, et al. The contribution of sonography to the measurement of intra-abdominal fat. $J$ Clin Ultrasound 1990;18:563-567.

[23] Kawasaki S, Aoki K, Hasegawa O, et al. Sonographic evaluation of visceral fat by measuring para- and perirenal fat. $J$ 
Clin Ultrasound 2008;36:129-133.

[24] Sun X, Han F, Miao W, Hou N, Cao Z, Zhang G. Sonographic evaluation of para- and perirenal fat thickness is an independent predictor of early kidney damage in obese patients. Int Urol Nephrol 2013;45:1589-1595.

[25] Lamacchia O, Nicastro V, Camarchio D, et al. Para- and perirenal fat thickness is an independent predictor of chronic kidney disease, increased renal resistance index and hyperuricaemia in type-2 diabetic patients. Nephrol Dial Transplant 2011;26:892-898.

[26] Weisinger JR, Kempson RL, Eldridge FL, Swenson RS. The nephrotic syndrome: a complication of massive obesity. Ann Intern Med 1974;81:440-447.

[27] Schiffrin EL, Lipman ML, Mann JF. Chronic kidney disease: effects on the cardiovascular system. Circulation 2007;116:85-97.

[28] de Boer IH, Sibley SD, Kestenbaum B, et al; Diabetes Control and Complications Trial/Epidemiology of Diabetes Interventions and Complications Study Research Group. Central obesity, incident microalbuminuria, and change in creatinine clearance in the epidemiology of diabetes interventions and complications study. J Am Soc Nephrol 2007;18:235-243.

[29] Valensi P, Assayag M, Busby M, Pariès J, Lormeau B, Attali JR. Microalbuminuria in obese patients with or without hypertension. Int J Obes Relat Metab Disord 1996;20:574-579.

[30] Kim H, Kim HJ, Shin N, et al. Visceral obesity is associated with microalbuminuria in nondiabetic Asians. Hypertens Res 2014;37:679-684.

[31] Drüeke TB, Massy ZA. Atherosclerosis in CKD: differences from the general population. Nat Rev Nephrol 2010;6:723735.

[32] Ritz E, Wanner C. Lipid abnormalities and cardiovascular risk in renal disease. J Am Soc Nephrol 2008;19:1065-1070.

[33] Scarpioni R, Ricardi M, Melfa L, Cristinelli L. Dyslipidemia in chronic kidney disease: are statins still indicated in reduction cardiovascular risk in patients on dialysis treatment? Cardiovasc Ther 2010;28:361-368.

[34] Wanner C, Krane V. Uremia-specific alterations in lipid metabolism. Blood Purif 2002;20:451-453.

[35] Adánez G, Castells MT, García Pérez B, et al. Effects of atorvastatin on progression-regression of renal injury in hyperlipidemic chickens. Histol Histopathol 2008;23:1131-1142.

[36] Feig DI, Kang DH, Johnson RJ. Uric acid and cardiovascular risk. N Engl J Med 2008;359:1811-1821.

[37] Kivity S, Kopel E, Maor E, et al. Association of serum uric acid and cardiovascular disease in healthy adults. Am J Cardiol 2013;111:1146-1151.

[38] Lv Q, Meng XF, He FF, et al. High serum uric acid and increased risk of type 2 diabetes: a systemic review and meta-analysis of prospective cohort studies. PLoS One 2013;8:e56864.

[39] Obermayr RP, Temml C, Gutjahr G, Knechtelsdorfer M, Oberbauer R, Klauser-Braun R. Elevated uric acid increases the risk for kidney disease. J Am Soc Nephrol 2008;19:24072413.

[40] Zoccali C, Maio R, Mallamaci F, Sesti G, Perticone F. Uric acid and endothelial dysfunction in essential hypertension. J Am Soc Nephrol 2006;17:1466-1471. 